\title{
Implementation and Sustainability of an Enhanced Pulmonary Rehabilitation Program in a single centre
}

\author{
Kim van der Braak \\ Utrecht University: Universiteit Utrecht \\ Joshua Wald \\ McMaster University \\ Catherine Tansey \\ McGill University Health Centre \\ Thais Paes \\ State University of Londrina: Universidade Estadual de Londrina \\ Maria Sedeno \\ McGill University Health Centre \\ Anne-Marie Selzler \\ University of Alberta \\ Michael Stickland \\ University of Alberta \\ Jean Bourbeau \\ McGill University Health Centre \\ Tania Janaudis-Ferreira ( $\nabla$ tania.janaudis-ferreira@mcgill.ca ) \\ McGill University https://orcid.org/0000-0003-0944-3791
}

\section{Research}

Keywords: Chronic Obstructive Pulmonary Disease, Pulmonary Rehabilitation, Implementation, RE-AIM Framework

Posted Date: November 13th, 2020

DOI: https://doi.org/10.21203/rs.3.rs-106900/v1

License: (a) (i) This work is licensed under a Creative Commons Attribution 4.0 International License. Read Full License 


\section{Abstract}

Background: Pulmonary rehabilitation (PR) has major benefits for patients with chronic obstructive pulmonary disease (COPD). The availability of PR in Canada is low. To facilitate implementation, a standardized and enhanced PR Program has been developed with a self-management education intervention that has been validated and shown to be effective. The objectives of our study were to assess the implementation of this program into a single site; determine the sustainability 18 months after implementation; and to identify the satisfaction with, facilitators of and barriers to implementation and sustainability of the program as perceived by patients with COPD and HCPs.

Methods: We conducted a prospective pre-post study which consisted of two phases: 1) the implementation phase (first six months after implementation) and 2) the sustainability phase (18 months after implementation). Guided by the RE-AIM framework, outcomes including: Reach (number of patients enrolled and demographics), Effectiveness (Change in patient outcomes), Adoption (HCPs' characteristics), Implementation (Program fidelity) and Maintenance (Patient outcomes at 3-month follow-up).

Results: Reach: Twenty-six patients were included for both phases (two different samples). Effectiveness: Clinically important improvements in patient outcomes were found for functional exercise capacity, knowledge, functional status and self-efficacy in both phases of the study. Adoption: All HCPs involved in PR $(\mathrm{N}=8)$ agreed to participate and used the program in both phases of the study. Implementation: Fidelity for the group education sessions ranged from 76-95\% in the implementation phase and from $82-88 \%$ in the sustainability phase. Maintenance (implementation phase): Clinical important improvements at 3-month follow-up were found in knowledge, self-efficacy for exercise and walking. Patients and HCPs were highly satisfied with the program. Lack of time was reported as the most common barrier and having longstanding procedures as the most common facilitator by HCPs to implementation and sustainability of the program.

Conclusions: The enhanced PR program was accepted by the patients and HCPs and could be reliably implemented and maintained at a single expert center. The program provided clinical benefits for patients in terms of functional capacity, knowledge and self-efficacy for walking. These findings will guide planning for wide scale dissemination and implementation of the program.

\section{Contributions To The Literature}

- This study is one of few studies regarding not only implementation but also sustainability in pulmonary rehabilitation (PR) which is an essential step for further research on PR.

- Self-management is included in the multi-component PR program, which is recommended for PR programs, but not widely integrated in existing or new PR programs. Moreover, the program materials provide guidance for health care professionals on self-management delivery according to principle of learning and cognition to modify patient's behavior.

- The approach of this study can be taken as an example by health care managers or individual health care professionals for implementing a new pulmonary rehabilitation program or to help improve the quality of an existing program.

\section{Background}

Chronic obstructive pulmonary disease (COPD) is characterized by symptoms such as coughing, dyspnea and exercise limitations ${ }^{1}$. Currently, COPD is the fourth leading cause of death worldwide and the prevalence is expected to increase in the future ${ }^{1}$. Individuals with COPD experience frequent exacerbations leading to an increase in symptoms and frequent hospitalizations which causes a significant impact on their quality of life and on the healthcare system ${ }^{2-4}$.

An essential component of the disease management in COPD is pulmonary rehabilitation (PR). PR is considered to be a standard of care intervention for individuals with COPD who remain symptomatic despite optimal bronchodilator therapy ${ }^{1,5-7}$. PR is defined as "a comprehensive intervention based on a thorough patient assessment followed by patient-tailored therapies that include, but are not limited to, exercise training, education, and behaviour change, designed to improve the physical and psychological condition of people with chronic respiratory disease and to promote the long-term adherence to health-enhancing behaviours" ${ }^{2}$. 
PR has been shown to be the most effective management strategy to improve shortness of breath, exercise tolerance and health related quality of life $\mathrm{e}^{5,6}$ in individuals with COPD while also having the potential to reduce exacerbations requiring hospital admissions ${ }^{9}$.

Despite the major benefits in people with $\operatorname{COPD}^{1,8,10}$, the availability of PR programs in Canada is low ${ }^{5,11,12}$. In addition, in Canada, there is currently a lack of agreed upon evidence-based standards for PR and a high degree of heterogeneity between programs. A survey of PR programs published in 2015 identified substantial variation between the 129 existing Canadian programs $^{12}$. The duration ranged from 1 week to $>12$ weeks, and exercise type and intensity, as well as educational topics delivered, varied widely across programs ${ }^{12}$.

Low program availability and quality have also been identified in other countries. In fact, recently, the American Thoracic and European Respiratory Societies (ATS/ERS) made recommendations to increase implementation and delivery of PR worldwide which included improving quality of PR programs and increasing awareness and knowledge of PR amongst healthcare professionals (HCPs), taxpayers and patients ${ }^{11,13}$.

To ensure the quality of care in PR programs in Canada and facilitate implementation, in 2016 a group of clinicians and researchers from across Canada developed a standardized and enhanced PR program with a self-management education intervention ${ }^{14}$ that has been validated and shown to be effective ${ }^{15}$. This program has recently been endorsed by the Canadian Thoracic Society and includes guidelines on patients' referral and assessments, exercise type, duration and intensity, educational topics and delivery as well as long-term follow-up. It incorporates an established self-management program adapted from the "Living Well with COPD" (LWWCOPD) program ${ }^{16-18}$ to create a comprehensive, multi-component PR program for individuals with COPD and provide guidance on self-management delivery according to principle of learning and cognition to modify patient's behavior. A randomized controlled trial conducted by our research team ${ }^{15}$ compared the enhanced PR program with a traditional PR program and showed that the enhanced PR program had similar improvements in physical activity, self-efficacy, and health outcomes as the traditional PR programs ${ }^{15}$. However, the enhanced program had the added benefit of reducing healthcare utilization $^{15}$.

The resources available within the enhanced PR program enable HCPs to improve current programs by using an evidence-based approach and can also be used to implement a new program in sites where PR is not yet available. Before the enhanced PR program can be implemented on a wider scale in Canada, the different phases and aspects of the implementation process of the program need to be well understood and evaluated. The RE-AIM framework ${ }^{19}$ (Reach, Effectiveness, Adoption, Implementation and Maintenance) is a model used to translate research evidence into practice and help plan programs and improve their chances of working in "real-world" settings. It also allows programs to be evaluated on the individual and organization levels on multiple domains. We conducted a study using the RE-AIM framework as a guide in order to:

1. Assess the implementation of the enhanced PR program into a single site;

2. Determine the sustainability of the implementation of the enhanced PR program 18 months after implementation;

3. Identify the satisfaction with, facilitators of and barriers to implementation and sustainability of the program as perceived by patients with COPD and HCPs in PR.

The lessons learned from this real-world evidence project can be used by other centers that intend to implement evidence-based PR programs in their sites.

\section{Methods}

\section{Design}

This single-site study has a prospective pre-post design using the RE-AIM framework ${ }^{19}$ to evaluate the implementation and sustainability of the enhanced PR program. The study consisted of two phases: 1 ) the implementation phase (first six months 
immediately after implementation) and 2) the sustainability phase (18 months after implementation). Both quantitative measures and open-ended survey-questions were used.

\section{Participants}

The program implementation was assessed on individual (patients) and organization levels (PR program/HCPs). The inclusion criteria were:

- Patients enrolled in the enhanced PR program, with a diagnosis of COPD confirmed by post-bronchodilator FEV1/FVC ratio of less than $0.7^{1}$.

- HCPs involved in the PR program were invited to participate. This included individuals licensed in nursing, respiratory therapy, physiotherapy, occupation therapy, social work and nutrition.

Exclusion criteria included: patients with a diagnosis other than COPD, with cognitive impairments who were unable to accurately complete questionnaires, and who could not understand either English or French.

\section{Study site and recruitment}

The study took place at the PR program of the Montreal Chest Institute (MCl) of the McGill University Health Centre, in Montreal, Canada. The existing outpatient PR program included both weekly group education sessions, as well as supervised exercise 3 times per week, for 6 weeks. No changes were made to the timing or duration of the program. The main changes made in the enhanced PR program related to the education material used as well as the format for delivery of education sessions. The previous educational sessions and materials had been developed by PR staff and contained a mixture of didactic and selfmanagement focused education styles, the sources were not standardized (e.g. they do not all refer to the LWCOPD program or care guidelines), and their quality and content were dependent on the professional expertise. The enhanced PR program contains 12 essential education topics including slides and patient handouts which were designed by a team of content experts and they encouraged patient participation and principles of self-management education. HCPs were asked to refer to the reference guide for self-management delivery and communication with individual and group patient sessions. All the new material contains standardized references to the LWWCOPD (log in to www.livingwellwithcopd.com, section "Rehabilitation" for details of education sessions and materials).

For the implementation phase, patients were recruited from the first three cycles of PR (6 weeks each) after implementation of the enhanced PR program (August 2017 until February 2018). Patients who were enrolled in the program 18 months after implementation (two cycles - March 2019 until June 2019) were included in the sustainability phase of the study. All HCPs working in the PR program during the implementation and sustainability phases were invited to participate and included when they provided informed consent.

\section{The enhanced PR program}

The enhanced PR program is based on current evidence and international guideline recommendations for PR with selfmanagement education based on the LWWCOPD program. The LWWCOPD is effective in promoting behaviour change, improving quality of life, and reducing hospital admissions in individuals with COPD ${ }^{16-18}$. More information on the enhanced PR program is shown in the Additional file 1.

\section{Implementation strategy}

Before implementation, all HCPs involved in the PR program at the $\mathrm{MCl}$ received an initial one-day group training with time set aside for questions and discussion regarding the implementation plan. During the training, the program content, goals and motivational communication techniques were presented and discussed. All HCPs involved in the program were shown how to access the resources of the program (e.g. reference guides, assessment forms as well as facilitator notes and slides for group education sessions). Feedback from HCP's involved in the program was incorporated into the final implementation plan. Members of the study team were available throughout the initial phase to answer questions and assist PR staff as required. One of the main adaptations done by the HCPs was to schedule the 12 essential topics of the CPRP during the available 10 group education sessions (e.g. some group education sessions would need to include 2 topics). 


\section{Measures}

The RE-AIM framework ${ }^{19}$ guided the outcomes for both objective 1 (implementation phase) and objective 2 (sustainability phase). The domains of the RE-AIM Framework are depicted in Table 1. Objective 3 pertained to both phases of the study.

Table 1

Domains of the RE-AIM framework.

\begin{tabular}{|c|c|c|c|}
\hline Domain & Definition & $\begin{array}{l}\text { Assessment } \\
\text { level }\end{array}$ & Operationalization within study \\
\hline Reach & $\begin{array}{l}\text { The absolute number, proportion, and } \\
\text { representativeness of individuals who are willing to } \\
\text { participate in a given initiative }\end{array}$ & $\begin{array}{l}\text { Individual } \\
\text { level }\end{array}$ & $\begin{array}{l}\text { Number of patients referred to } \\
\text { program, number of patients } \\
\text { accepting to participate in the } \\
\text { program and characteristics }\end{array}$ \\
\hline Effectiveness & $\begin{array}{l}\text { The impact of an intervention on important outcomes, } \\
\text { including potential negative effects, quality of life, and } \\
\text { economic outcomes. }\end{array}$ & $\begin{array}{l}\text { Individual } \\
\text { level }\end{array}$ & $\begin{array}{l}\text { Clinical outcomes of patients } \\
\text { pre and post program }\end{array}$ \\
\hline Adoption & $\begin{array}{l}\text { The absolute number, proportion, and } \\
\text { representativeness of settings and intervention agents } \\
\text { who are willing to initiate a program. }\end{array}$ & $\begin{array}{l}\text { Organization } \\
\text { level }\end{array}$ & $\begin{array}{l}\text { The proportion of HCPs } \\
\text { following the enhanced PR } \\
\text { program out of the total HCPs } \\
\text { involved in PR at the study site } \\
\text { and their characteristics }\end{array}$ \\
\hline Implementation & $\begin{array}{l}\text { At the setting level, implementation refers to the } \\
\text { intervention agents' fidelity to the various elements of } \\
\text { an intervention's protocol. This includes consistency of } \\
\text { delivery as intended and the time and cost of the } \\
\text { intervention. }\end{array}$ & $\begin{array}{l}\text { Organization } \\
\text { level }\end{array}$ & $\begin{array}{l}\text { Fidelity on content and delivery } \\
\text { of the group education } \\
\text { sessions by the HCPs involved }\end{array}$ \\
\hline \multirow[t]{2}{*}{ Maintenance } & $\begin{array}{l}\text { At the individual level, maintenance has been defined } \\
\text { as the long-term effects of a program on outcomes } \\
\text { after } 6 \text { or more months after the most recent } \\
\text { intervention contact. }\end{array}$ & $\begin{array}{l}\text { Individual } \\
\text { level }\end{array}$ & $\begin{array}{l}\text { Clinical outcomes of patients at } \\
\text { 3-month follow-up }\end{array}$ \\
\hline & $\begin{array}{l}\text { The extent to which a program or policy becomes } \\
\text { institutionalized or part of the routine organizational } \\
\text { practices and policies. }\end{array}$ & $\begin{array}{l}\text { Organization } \\
\text { level }\end{array}$ & $\begin{array}{l}\text { Outcomes on domains Reach, } \\
\text { Effectiveness, Adoption and } \\
\text { Implementation as described } \\
\text { above within new PR cycles } 18 \\
\text { months after initial } \\
\text { implementation of the program. }\end{array}$ \\
\hline
\end{tabular}

\section{Implementation phase}

\section{Reach}

Number of individuals referred for PR, number of patients with COPD participating in the enhanced PR program within the study period, reasons for not participating and characteristics of the included individuals.

\section{Effectiveness}

Clinical outcomes pre and post program (functional exercise capacity, health status, patient report of difficulty or ease in daily activities, knowledge and self-efficacy) (Table 2). 
Table 2

Measures and instruments used to assess effectiveness.

\begin{tabular}{|c|c|c|c|}
\hline Outcome measure & $\begin{array}{l}\text { Measurement } \\
\text { instrument }\end{array}$ & $\begin{array}{l}\text { Clinical important } \\
\text { difference }\end{array}$ & How data was collected \\
\hline Functional exercise capacity & $6 \mathrm{MWT}$ & $\geq 33 \mathrm{~m} \uparrow$ & \multirow[t]{2}{*}{ Part of program, obtained by HCP's } \\
\hline Health status & CAT & $\geq 2$ points $\downarrow$ & \\
\hline $\begin{array}{l}\text { Patient report of difficulty or ease in } \\
\text { daily activities }\end{array}$ & FPI-SF & $\geq 0.5$ points $\uparrow$ & \multirow[t]{4}{*}{$\begin{array}{l}\text { Additional questionnaires, obtained } \\
\text { by researcher }\end{array}$} \\
\hline \multirow[t]{2}{*}{ Knowledge } & LINQ & $\geq 1$ point $\downarrow$ & \\
\hline & BCKQ & $\geq 3 \% \uparrow$ & \\
\hline Self-efficacy & $\begin{array}{l}\text { SEAMS, SEWS and } \\
\text { MSEES* }\end{array}$ & $\geq 10 \% \uparrow$ & \\
\hline \multicolumn{4}{|c|}{ Tan increase of clinical important difference is a positive outcome. } \\
\hline \multicolumn{4}{|c|}{$\downarrow$ a decrease of clinical important difference is a positive outcome. } \\
\hline \multicolumn{4}{|c|}{ *score from the MSEES is split into 4 subscores following the example of Selzler et al. 2019.} \\
\hline \multicolumn{4}{|c|}{$\begin{array}{l}\text { Abbreviations: } 6 M W T=\text { Six Minute Walk Test, CAT = COPD Assessment Test, } H C P=\text { Health care professionals, FPI-SF = } \\
\text { Functional Performance Inventory Short Form, LINQ = Lung Information Needs Questionnaire, BCKQ = Bristol COPD Knowledge } \\
\text { Questionnaire, SEAMS = Self-Efficacy for Appropriate Medication use Scale, SEWS = Self-Efficacy for Walking Scale, MSEES = } \\
\text { Multidimensional Self-Efficacy for Exercise Scale }\end{array}$} \\
\hline
\end{tabular}

\section{Adoption}

The proportion of HCPs that follow the enhanced PR program out of the total HCPs involved in PR at the study site. Characteristics of the HCPs of the site (e.g. experience in PR and professional qualifications). Adoption also includes the willingness of HCPs to adopt the new program which is covered in the survey for HCPs.

\section{Implementation}

Fidelity of the group education sessions using a checklist developed by investigators (Additional file 2) that evaluated the content ( 4 or 5 items) and delivery (3 items) of the education sessions. The components of this checklist were scored on a 7-point Likert scale ranging from (1) Not addressed to (7) All aspects covered clearly and in depth. One of the researchers attended a sample of the group education sessions to score.

\section{Maintenance}

Clinical outcomes (knowledge, self-efficacy and the patient report of ease or difficulty in daily activities) at 3-month follow-up.

\section{Sustainability phase}

As the implementation phase was a learning process, some outcomes were changed or added for the sustainability phase. The outcomes for the Reach and Effectiveness domains were the same as the implementation phase. Changes in staff were tracked for the domain Adoption.

For the implementation domain, the same fidelity checklist was used to assess the group education sessions. In addition, the exercise sessions were assessed for fidelity. The duration, number of sessions, home exercise, types of exercise, monitoring and the use of strategies to determine exercise intensity were compared to the programs' recommendations described in the Additional file 1. These data were extracted from the patients' medical records. To understand how the HCPs were dealing with the enhanced PR program 18 months after implementation, one of the investigators observed and communicated with the all dedicated HCPs in their weekly meetings during the study period. At the group education sessions when one of the investigators 
was present, she observed and communicated with patients as well. This type of observation is called observer-as-participant by Gold $(1958)^{20}$. Notes and ideas were put in a digital logbook.

As all outcomes above were assessed 18 months after implementation, further outcomes for the domain "Maintenance" would be redundant and therefore were not included in this phase.

\section{Satisfaction with, facilitators of and barriers to implementing and sustaining the enhanced PR program}

For objective 3, patients and HCPs were asked to fill out surveys in both the implementation and the sustainability phases (Additional file 3). Patients were asked about their satisfaction with the program components and potential barriers for participation. HCPs were asked about their satisfaction with the content and introduction of the program and potential barriers for implementation and maintenance of the program.

To further assess the barriers and facilitators of the implementation and maintenance as perceived by the HCPs in the sustainability phase, HCPs were asked to complete an adjusted version of the Determinants of Implementation Behavior Questionnaire (DIBQ) which is based on the Theoretical Domains Framework (TDF) 21,22 .

\section{Analysis}

Outcomes on reach, adoption and implementation were analyzed descriptively. T-tests for patient characteristics were performed to identify statistical differences in participants that completed and participants that did not complete the program in the implementation phase. This was not done for the sustainability phase as there was only one participant that did not complete the program. From the fidelity scores of the group education sessions, a percentage was calculated for each group education session, with 'good' fidelity $\geq 5$.

Changes in patient outcomes were calculated. Because of low sample size no statistical tests were performed. Therefore, the number and percentage of participants that improved more or equal to the minimal clinical important difference (MCID) were calculated. This data was included in the additional files. The MCIDs used were based on the literature as depicted in Table 2. No MCID was found in the literature for the Functional Performance Inventory Short Form (FPI-SF) and the self-efficacy questionnaires. Based on clinical expertise we used an increase of 0.5 points as minimal change for the FPI-SF and an increase of $10 \%$ as minimal change for the self-efficacy questionnaires. This method was also used for the patient outcomes at the 3month follow-up.

To identify barriers and facilitators, open-ended questions from the surveys were summarized into a comprehensive list.

Domain-scores were calculated for the DIBQ. Following the example of Kunstler et al. ${ }^{23}$, the domain-scores were categorized in disagree (values 1 to 3.5), neither agree or disagree (values 3.5 to 4.5) and agree (values 4.5 to 6). Frequencies were calculated for all categories. SPSS (IBM Corp. Released 2015. IBM SPSS Statistics for Windows, Version 23.0. Armonk, NY: IBM Corp) was used for the descriptive analysis.

\section{Results}

\section{REACH: Implementation and Sustainability phases}

Figure 1 and 2 present the patient referral and participant inclusion for the implementation and the sustainability phases respectively. In the implementation phase, 54 (70\%) patients out of 77 referred patients agreed to participate in a PR program. In the sustainability phase, 24 (75\%) out of 32 referred patients agreed to participate in a PR program. Patients who did an adjusted program or a home program instead of the enhanced PR program because of their individual needs, were not included in the study. Sixteen patients were included in the implementation phase and ten patients in the sustainability phase. The characteristics of these participants are depicted in Table 3. 
Table 3

Domain Reach: Participant characteristics.

\begin{tabular}{|c|c|c|c|c|}
\hline Characteristic & Implementation phas & & & $\begin{array}{l}\text { Sustainability } \\
\text { phase }\end{array}$ \\
\hline \multirow[t]{2}{*}{ Mean \pm SD (range) $N=16$} & \multicolumn{2}{|l|}{ Mean \pm SD } & \multirow{2}{*}{$\begin{array}{l}\text { Mean } \pm \text { SD (range) } \\
N=10\end{array}$} & \\
\hline & $\begin{array}{l}\text { Completed the study } \\
N=11\end{array}$ & $\begin{array}{l}\text { Did not complete the } \\
\text { study } N=5\end{array}$ & & \\
\hline Age & $69.6 \pm 7.5(57-87)$ & $69.5 \pm 7.5$ & $70 \pm 8.4$ & $\begin{array}{l}67.4 \pm 6.8(53- \\
76)\end{array}$ \\
\hline Sex, Female, n (\%) & $9(56)$ & $6(54.5)$ & $3(60)$ & $7(70)$ \\
\hline BMI & $26.7 \pm 9.7(15-59)$ & $25.2 \pm 4.4$ & $30 \pm 16.9$ & $\begin{array}{l}29.2 \pm 8.0(17- \\
41)\end{array}$ \\
\hline $\begin{array}{l}\text { Smoking status, ex-smoker, } \mathrm{n} \\
(\%)\end{array}$ & $16(100)$ & $11(100)$ & $5(100)$ & $10(100)$ \\
\hline Pack-years & $\begin{array}{l}46.6 \pm 23.8(25- \\
120)\end{array}$ & $38.75 \pm 8.8$ & $59.2 \pm 35.3$ & $\begin{array}{l}41.1 \pm 8.7(30- \\
52)\end{array}$ \\
\hline \multicolumn{5}{|l|}{ Comorbidities } \\
\hline CVD, n (\%) & $1(6.3)$ & $1(9.1)$ & $0(0)$ & $1(10)$ \\
\hline Asthma, n (\%) & $4(25)$ & $1(9.1)$ & $3(60)$ & $2(20)$ \\
\hline Other lung disease, $\mathrm{n}(\%)$ & $3(18.8)$ & $2(18.2)$ & $1(20)$ & $3(30)$ \\
\hline Other, n (\%) & $0(0)$ & $0(0)$ & $0(0)$ & $3(30)$ \\
\hline FEV1\% predicted & $47.5 \pm 17.1(20-76)$ & $49.9 \pm 17.2$ & $42.2 \pm 17.7$ & $\begin{array}{l}56.4 \pm 11.9(36- \\
79)\end{array}$ \\
\hline FEV/FVC ratio & $\begin{array}{l}0.45 \pm 0.11(0.19- \\
0.66)\end{array}$ & $0.45 \pm 0.12$ & $0.43 \pm 0.09$ & $\begin{array}{l}0.52 \pm 0.11 \\
(0.32-0.71)\end{array}$ \\
\hline 6MWT (m) & $\begin{array}{l}339 \pm 102(100- \\
460)\end{array}$ & $381 \pm 48$ & $245 \pm 130$ & $\begin{array}{l}369 \pm 107(140- \\
485)\end{array}$ \\
\hline \multicolumn{5}{|l|}{ MRC-score category, n (\%) } \\
\hline 2 & $5(31.3)$ & $4(36)$ & $1(20)$ & $1(10)$ \\
\hline 3 & $6(37.5)$ & $5(46)$ & $1(20)$ & $4(40)$ \\
\hline 4 & $3(18.8)$ & $1(9)$ & $2(40)$ & $4(40)$ \\
\hline 5 & $1(6.3)$ & 0 & $1(20)$ & $1(10)$ \\
\hline CAT-score & $16.7 \pm 6.3(8-28)$ & $13.9 \pm 4.4$ & $24.5 \pm 3.1$ & $\begin{array}{l}21.0 \pm 6.9(12- \\
33)\end{array}$ \\
\hline HADS Anxiety & $6.8 \pm 3.1(2-13)$ & $6.7 \pm 3.5$ & $7.0 \pm 2.6$ & $8.1 \pm 4.6(3-15)$ \\
\hline HADS Depression & $5.6 \pm 3.8(1-12)$ & $5.0 \pm 3.9$ & $6.8 \pm 4.0$ & $6.5 \pm 3.3(2-11)$ \\
\hline HADS total & $12.5 \pm 6.0(6-12)$ & $11.7 \pm 6.0$ & $13.8 \pm 6.6$ & $14.6 \pm 7.1(6-25)$ \\
\hline BODE index & $3.6 \pm 2.5(0-10)$ & $2.7 \pm 1.8$ & $5.4 \pm 3.0$ & $3.3 \pm 1.9(1-7)$ \\
\hline
\end{tabular}

Abbreviations: $S D=$ standard deviation, $N=$ number of patients, $B M I=$ Body Mass Index,$C V D=$ Cardiovascular disease, $F E V 1=$ Forced Expiration Volume in one second, 6MWT = 6 Minute Walk Test, MRC-score = Medical Research Council score, CATscore $=$ COPD Assessment Test score, HADS = Hospital Anxiety and Depression Scale, BODE = Body mass index, airflow Obstruction, Dyspnea and Exercise capacity.

* Number of education/exercise sessions attended / total number of education/exercise sessions (\%) 


\begin{tabular}{|c|c|c|c|c|}
\hline Characteristic & Implementation p & & & $\begin{array}{l}\text { Sustainability } \\
\text { phase }\end{array}$ \\
\hline $\begin{array}{l}\text { Attendance group education } \\
\text { sessions* }\end{array}$ & $8.4 / 11.1(75 \%)$ & 10.1/11.5 (90\%) & $3.5 / 10.2(34 \%)$ & $6.3 / 12(53 \%)$ \\
\hline $\begin{array}{l}\text { Attendance exercise } \\
\text { sessions* }\end{array}$ & 13.2/16.8 (77\%) & 15.5/17.3 (89\%) & 7.0/15.6 (43\%) & 14.8/15 (99\%) \\
\hline \multicolumn{5}{|c|}{$\begin{array}{l}\text { Abbreviations: } S D=\text { standard deviation, } N=\text { number of patients, } B M I=B o d y \text { Mass Index, } C V D=\text { Cardiovascular disease, FEV1 = } \\
\text { Forced Expiration Volume in one second, } 6 M W T=6 \text { Minute Walk Test, MRC-score = Medical Research Council score, CAT- } \\
\text { score =COPD Assessment Test score, HADS = Hospital Anxiety and Depression Scale, BODE = Body mass index, airflow } \\
\text { Obstruction, Dyspnea and Exercise capacity. }\end{array}$} \\
\hline \multicolumn{5}{|c|}{ * Number of education/exercise sessions attended / total number of education/exercise sessions (\%) } \\
\hline
\end{tabular}

In the implementation phase, five (31\%) patients dropped out, because of exacerbation $(N=4)$ or another illness $(N=1)$. These patients had a higher CAT-score (mean difference 10.6 points, sd 2.4, $\mathrm{p}=0.001$ ) and a higher BODE-index (mean difference 2.7 points, sd 1.1, $p=0.04$ ) which was significantly higher than the patients who completed the PR program in that phase. In the sustainability phase only one patient dropped out (Fig. 2).

Not all patients included in the study completed all components of the enhanced program. One patient completed only the education component of the program (implementation phase) and three patients only completed the exercise component ( $\mathrm{N}=1$ from implementation phase, $N=2$ sustainability phase). Two patients had the program extended because they had slow progression and would benefit from more exercise sessions.

\section{Adoption, Implementation, Effectiveness and Maintenance: Implementation phase}

The enhanced PR program was adopted by all HCPs $(\mathrm{N}=8,100 \%)$ working in PR program at the $\mathrm{MCl}$, all of whom accepted to participate in the study. Their characteristics are depicted in Table 4.

Table 4

Domain Adoption: Characteristics of the HCPs.

\begin{tabular}{|ll|}
\hline Characteristics & Frequencies (\%) \\
\hline Work experience in years, mean \pm SD (range) & $16 \pm 10(1-35)$ \\
\hline Disciplines & $3(37.5 \%)$ \\
\hline Nurse & $1(12.5 \%)$ \\
\hline Physical therapist & $1(12.5 \%)$ \\
\hline Social worker & $1(12.5 \%)$ \\
\hline Nutritionist & $1(12.5 \%)$ \\
\hline Occupational therapist & $1(12.5 \%)$ \\
\hline Respiratory therapist & $8(100 \%)$ \\
\hline Education & $1(12.5 \%)$ \\
\hline Bachelor & $4(50 \%)$ \\
\hline Master & \\
\hline Attended relevant courses/ conferences & \\
\hline These HCPs participated in the pilot implementation and sustainability study & \\
\hline Abbreviations: SD = standard deviation & \\
\hline
\end{tabular}


The individual education sessions that are part of the enhanced PR program recommendations were not given by the HCPs in the standardized format and could therefore not be assessed for the study. Fourteen group education sessions were scored for implementation fidelity (Table 5). From these sessions, $76 \%$ of the items for content and $95 \%$ of the items for delivery received a good fidelity score (a score $\geq 5$ ). The number of participants present at the education sessions varied between two and ten patients, with a median of four patients.

Table 5

Domain Implementation: Fidelity scores for the group education sessions of the implementation and sustainability phase.

\begin{tabular}{|c|c|c|c|c|c|c|}
\hline \multirow{3}{*}{$\begin{array}{l}\text { Session } \\
\text { number }\end{array}$} & \multirow[t]{3}{*}{ Session name } & \multirow[t]{3}{*}{ Given by } & \multicolumn{4}{|c|}{ Mean ratio of good fidelity* (\%) } \\
\hline & & & \multicolumn{2}{|c|}{$\begin{array}{l}\text { Implementation } \\
\text { phase }\end{array}$} & \multicolumn{2}{|c|}{ Sustainability phase } \\
\hline & & & Content & Delivery & Content & Delivery \\
\hline$\# 1^{1}$ & Living well and breathing easy & Nurse & $4 / 5(80)$ & $\begin{array}{l}3 / 3 \\
(100)\end{array}$ & $4 / 5(80)$ & $\begin{array}{l}2.3 / 3 \\
(77)\end{array}$ \\
\hline$\# 4^{1}$ & Breathing management & Physiotherapist & $\begin{array}{l}5 / 5 \\
(100)\end{array}$ & $\begin{array}{l}3 / 3 \\
(100)\end{array}$ & $\begin{array}{l}3.7 / 5 \\
(74)\end{array}$ & $\begin{array}{l}2.3 / 3 \\
(77)\end{array}$ \\
\hline \#5 & Conserving energy & $\begin{array}{l}\text { Occupational } \\
\text { therapist }\end{array}$ & $\begin{array}{l}2.5 / 4 \\
(62.5)\end{array}$ & $\begin{array}{l}3 / 3 \\
(100)\end{array}$ & $\begin{array}{l}3.5 / 4 \\
(87.5)\end{array}$ & $\begin{array}{l}2.75 / 3 \\
(92)\end{array}$ \\
\hline \#6 & Medications for chronic lung disease & Nurse & $\begin{array}{l}4.5 / 5 \\
(90)\end{array}$ & $\begin{array}{l}3 / 3 \\
(100)\end{array}$ & $\begin{array}{l}4.5 / 5 \\
(90)\end{array}$ & $\begin{array}{l}3 / 3 \\
(100)\end{array}$ \\
\hline \#7 & Inhaler devices & $\begin{array}{l}\text { Respiratory } \\
\text { therapist }\end{array}$ & $\begin{array}{l}4 / 4 \\
(100)\end{array}$ & $\begin{array}{l}3 / 3 \\
(100)\end{array}$ & $\begin{array}{l}3.3 / 4 \\
(82.5)\end{array}$ & $\begin{array}{l}3 / 3 \\
(100)\end{array}$ \\
\hline \#8 & $\begin{array}{l}\text { Integrating an exercise program into } \\
\text { your life }\end{array}$ & Physiotherapist & $\begin{array}{l}\text { Not } \\
\text { scored }\end{array}$ & $\begin{array}{l}\text { Not } \\
\text { scored }\end{array}$ & $3 / 5(60)$ & $\begin{array}{l}3 / 3 \\
(100)\end{array}$ \\
\hline \#9 & Management of respiratory infections & Nurse & $4 / 5(80)$ & $\begin{array}{l}3 / 3 \\
(100)\end{array}$ & $\begin{array}{l}4.5 / 5 \\
(90)\end{array}$ & $\begin{array}{l}3 / 3 \\
(100)\end{array}$ \\
\hline$\# 10$ & $\begin{array}{l}\text { Management of aggravating } \\
\text { environmental factors }\end{array}$ & Nurse & $\begin{array}{l}4 / 4 \\
(100)\end{array}$ & $\begin{array}{l}3 / 3 \\
(100)\end{array}$ & $\begin{array}{l}3.5 / 4 \\
(87.5)\end{array}$ & $\begin{array}{l}3 / 3 \\
(100)\end{array}$ \\
\hline$\# 11$ & Management of anxiety and stress & Social worker & $\begin{array}{l}2.5 / 5 \\
(50)\end{array}$ & $\begin{array}{l}3 / 3 \\
(100)\end{array}$ & $4 / 5(80)$ & $\begin{array}{l}3 / 3 \\
(100)\end{array}$ \\
\hline$\# 12$ & Nutrition and lung health & Nutritionist & $\begin{array}{l}2.7 / 4 \\
(68)\end{array}$ & $\begin{array}{l}1.7 / 3 \\
(57)\end{array}$ & $3 / 4(75)$ & $\begin{array}{l}1.7 / 3 \\
(57)\end{array}$ \\
\hline Ratio of $c$ & fidelity total ${ }^{2}$ (mean percentage) & & $\begin{array}{l}48 / 63 \\
(76)\end{array}$ & $\begin{array}{l}38 / 40 \\
(95)\end{array}$ & $\begin{array}{l}93 / 113 \\
(82)\end{array}$ & $\begin{array}{l}66 / 75 \\
(88)\end{array}$ \\
\hline \multicolumn{7}{|c|}{${ }^{*}$ Good fidelity is defined as a score $\geq 5$ (Mostly complete with minor omissions) } \\
\hline \multicolumn{7}{|c|}{$\begin{array}{l}1 \text { Session \#1 (Living well and breathing easy) \& \#3 (Living well with chronic lung disease) and sessions \#2 (Exercise) \& \#4 } \\
\text { (Breathing management) were merged. The score forms for session \#1 and for session \#4 were used. }\end{array}$} \\
\hline
\end{tabular}

The session 'Integrating an exercise program in your life' could not be scored for the study, because the topic was discussed with the patients during an exercise session when the researcher was not present.

Outcomes related to the program's effectiveness and maintenance at the patient level (the patient outcomes directly post-program and at 3-months follow-up), are depicted in Table 6 and Table 7. Clinically important improvements were shown in functional exercise capacity, knowledge, functional status, self-efficacy outcomes and some self-reported functional performance outcomes directly post-program. At the 3-month follow-up, clinically important improvements were shown in knowledge, self-efficacy outcomes and some self-reported functional performance outcomes compared to baseline. 
Table 6

Domain Effectiveness: Patient outcomes implementation phase.

\begin{tabular}{|c|c|c|c|c|c|c|}
\hline Outcome & $\begin{array}{l}\text { Measurement } \\
\text { instrument }\end{array}$ & $\begin{array}{l}\text { Clinical important } \\
\text { difference }\end{array}$ & $\begin{array}{l}\text { Improved N } \\
(\%)^{*}\end{array}$ & $\begin{array}{l}\text { Not } \\
\text { improved } \\
N(\%)^{\star *}\end{array}$ & $\begin{array}{l}\text { Missing N } \\
(\%)\end{array}$ & $\begin{array}{l}\text { Total } \\
\mathbf{N}\end{array}$ \\
\hline $\begin{array}{l}\text { Functional exercise } \\
\text { capacity }\end{array}$ & $6 \mathrm{MWT}$ & $\geq 33 \mathrm{~m} \uparrow$ & $7(64)$ & $2(18)$ & $2(18)$ & 11 \\
\hline Knowledge & LINQ & $\geq 1$ point $\downarrow$ & $7(64)$ & $3(27)$ & $1(9)$ & 11 \\
\hline Functional status & CAT-score & $\geq 2$ points $\downarrow$ & $4(36)$ & $5(46)$ & $2(18)$ & 11 \\
\hline \multirow{7}{*}{$\begin{array}{l}\text { Self-reported functional } \\
\text { performance }\end{array}$} & FPI-SF Body care & $\geq 0.5$ points $\uparrow$ & $0(0)$ & $10(91)$ & $1(9)$ & 11 \\
\hline & FPI-SF Household & $\geq 0.5$ points $\uparrow$ & $0(0)$ & $10(91)$ & $1(9)$ & 11 \\
\hline & $\begin{array}{l}\text { FPI-SF Physical } \\
\text { exercise }\end{array}$ & $\geq 0.5$ points $\uparrow$ & $2(18)$ & $8(73)$ & $1(9)$ & 11 \\
\hline & FPI-SF Recreation & $\geq 0.5$ points $\uparrow$ & $1(9)$ & $9(82)$ & $1(9)$ & 11 \\
\hline & FPI-SF Spiritual & $\geq 0.5$ points $\uparrow$ & $1(9)$ & $9(82)$ & $1(9)$ & 11 \\
\hline & FPI-SF Social & $\geq 0.5$ points $\uparrow$ & $0(0)$ & $10(91)$ & $1(9)$ & 11 \\
\hline & FPI-SF Total & $\geq 0.5$ points $\uparrow$ & $0(0)$ & $10(91)$ & $1(9)$ & 11 \\
\hline \multirow[t]{7}{*}{ Self-efficacy } & MSEES total mean & \multirow[t]{5}{*}{$\geq 10 \% \uparrow$} & $3(27)$ & $6(55)$ & $2(18)$ & 11 \\
\hline & Task SE & & $2(18)$ & $4(36)$ & $5(46)$ & 11 \\
\hline & Exercise coping & & $1(9)$ & $5(46)$ & $5(46)$ & 11 \\
\hline & Scheduling SE & & $1(9)$ & $4(36)$ & $6(55)$ & 11 \\
\hline & Breathing coping & & $4(36)$ & $2(18)$ & $5(46)$ & 11 \\
\hline & SEWS total mean & $\geq 10 \% \uparrow$ & $4(36)$ & $6(55)$ & $1(9)$ & 11 \\
\hline & SEAMS total mean & $\geq 10 \% \uparrow$ & $1(9)$ & $8(73)$ & $2(18)$ & 11 \\
\hline \multicolumn{7}{|c|}{${ }^{*}$ Number of patients that improved exceeding the clinical important difference. } \\
\hline \multicolumn{7}{|c|}{$\begin{array}{l}\text { ** Number of patients that did not improve or had an improvement that did not exceed the clinical important difference. Tan } \\
\text { increase of clinical important difference is a positive outcome. }\end{array}$} \\
\hline \multicolumn{7}{|c|}{$\downarrow$ a decrease of clinical important difference is a positive outcome. } \\
\hline \multicolumn{7}{|c|}{$\begin{array}{l}\text { Abbreviations: } 6 M W T=6 \text { Minute Walk Test, } L I N Q=L \text { ung Information Needs Questionnaire, BCKQ = Bristol COPD Knowledge } \\
\text { Questionnaire, CAT = COPD Assessment Test, FPI-SF = Functional Performance Inventory-Short Form, MSEES = } \\
\text { Multidimensional Self-Efficacy for Exercise Scale, SE = Self-Efficacy, SEWS = Self-Efficacy for Walking Scale, SEAMS = Self- } \\
\text { Efficacy for Appropriate Medication Use Scale }\end{array}$} \\
\hline
\end{tabular}


Table 7

Domain Maintenance on patient level: Patient outcomes at 3 months follow-up vs. baseline / post-program.

\begin{tabular}{|c|c|c|c|c|c|c|c|c|c|}
\hline \multirow[t]{3}{*}{ Outcome } & \multirow{3}{*}{$\begin{array}{l}\text { Measurement } \\
\text { instrument }\end{array}$} & \multirow{3}{*}{$\begin{array}{l}\text { Clinical } \\
\text { important } \\
\text { difference }\end{array}$} & \multicolumn{3}{|c|}{ follow up vs. baseline } & \multicolumn{3}{|c|}{ follow up vs. post-program } & \multirow{3}{*}{$\begin{array}{l}\text { Total } \\
\text { N }\end{array}$} \\
\hline & & & $\begin{array}{l}\text { Improved } \\
\mathrm{N}(\%)^{*}\end{array}$ & $\begin{array}{l}\text { Not } \\
\text { improved }\end{array}$ & $\begin{array}{l}\text { Missing } \\
\mathbf{N}(\%)\end{array}$ & $\begin{array}{l}\text { Improved } \\
\mathrm{N}(\%)^{*}\end{array}$ & $\begin{array}{l}\text { Not } \\
\text { improved }\end{array}$ & $\begin{array}{l}\text { Missing } \\
\mathrm{N}(\%)\end{array}$ & \\
\hline & & & & \multicolumn{3}{|l|}{$N(\%)^{\star \star}$} & \multicolumn{2}{|l|}{$\mathrm{N}(\%)^{* *}$} & \\
\hline Knowledge & LINQ & $\geq 1$ point & $8(73)$ & $3(27)$ & $0(0)$ & $6(55)$ & $4(36)$ & $1(9)$ & 11 \\
\hline \multirow{7}{*}{$\begin{array}{l}\text { Self-reported } \\
\text { functional } \\
\text { performance }\end{array}$} & $\begin{array}{l}\text { FPI-SF Body } \\
\text { care }\end{array}$ & $\begin{array}{l}\geq 0.5 \\
\text { points } \uparrow\end{array}$ & $2(18)$ & $9(82)$ & $0(0)$ & $0(0)$ & $10(91)$ & $1(9)$ & 11 \\
\hline & $\begin{array}{l}\text { FPI-SF } \\
\text { Household }\end{array}$ & $\begin{array}{l}\geq 0.5 \\
\text { points } \uparrow\end{array}$ & $2(18)$ & $9(82)$ & $0(0)$ & $0(0)$ & $10(91)$ & $1(9)$ & 11 \\
\hline & $\begin{array}{l}\text { FPI-SF } \\
\text { Physical } \\
\text { exercise }\end{array}$ & $\begin{array}{l}\geq 0.5 \\
\text { points } \uparrow\end{array}$ & $0(0)$ & $11(100)$ & $0(0)$ & $2(18)$ & $8(73)$ & $1(9)$ & 11 \\
\hline & $\begin{array}{l}\text { FPI-SF } \\
\text { Recreation }\end{array}$ & $\begin{array}{l}\geq 0.5 \\
\text { points } \uparrow\end{array}$ & $1(9)$ & $10(91)$ & $0(0)$ & $0(0)$ & $10(91)$ & $1(9)$ & 11 \\
\hline & $\begin{array}{l}\text { FPI-SF } \\
\text { Spiritual }\end{array}$ & $\begin{array}{l}\geq 0.5 \\
\text { points } \uparrow\end{array}$ & $5(46)$ & $6(55)$ & $0(0)$ & $0(0)$ & $10(91)$ & $1(9)$ & 11 \\
\hline & FPI-SF Social & $\begin{array}{l}\geq 0.5 \\
\text { points } \uparrow\end{array}$ & $2(18)$ & $9(82)$ & $0(0)$ & $0(0)$ & $10(91)$ & $1(9)$ & 11 \\
\hline & FPI-SF Total & $\begin{array}{l}\geq 0.5 \\
\text { points } \uparrow\end{array}$ & $1(9)$ & $10(91)$ & $0(0)$ & $0(0)$ & $10(91)$ & $1(9)$ & 11 \\
\hline \multirow[t]{7}{*}{ Self-efficacy } & $\begin{array}{l}\text { MSEES total } \\
\text { mean }\end{array}$ & \multirow[t]{5}{*}{$\geq 10 \% \uparrow$} & $6(55)$ & $3(27)$ & $2(18)$ & $1(9)$ & $8(73)$ & $2(18)$ & 11 \\
\hline & Task SE & & $2(18)$ & $3(27)$ & $6(55)$ & $2(18)$ & $6(55)$ & $3(27)$ & 11 \\
\hline & $\begin{array}{l}\text { Exercise } \\
\text { coping }\end{array}$ & & $3(27)$ & $3(27)$ & $5(46)$ & $5(46)$ & $3(27)$ & $3(27)$ & 11 \\
\hline & $\begin{array}{l}\text { Scheduling } \\
\text { SE }\end{array}$ & & $3(27)$ & $3(27)$ & $5(46)$ & $1(9)$ & $6(55)$ & $4(36)$ & 11 \\
\hline & $\begin{array}{l}\text { Breathing } \\
\text { coping }\end{array}$ & & $5(46)$ & $1(9)$ & $5(46)$ & $1(9)$ & $5(46)$ & $5(46)$ & 11 \\
\hline & $\begin{array}{l}\text { SEWS total } \\
\text { mean }\end{array}$ & $\geq 10 \% \uparrow$ & $5(46)$ & $4(36)$ & $2(18)$ & $0(0)$ & $8(73)$ & $3(27)$ & 11 \\
\hline & $\begin{array}{l}\text { SEAMS total } \\
\text { mean }\end{array}$ & $\geq 10 \% \uparrow$ & $1(9)$ & $8(73)$ & $2(18)$ & $0(0)$ & $8(73)$ & $3(27)$ & 11 \\
\hline \multicolumn{10}{|c|}{ This data was only obtained in the implementation phase of the study. } \\
\hline \multicolumn{10}{|c|}{${ }^{*}$ Number of patients that improved exceeding the clinical important difference. } \\
\hline \multicolumn{10}{|c|}{$\begin{array}{l}{ }^{*} \text { Number of patients that did not improve or had an improvement that did not exceed the clinical important difference. Tan } \\
\text { increase of clinical important difference is a positive outcome. }\end{array}$} \\
\hline \multicolumn{10}{|c|}{$\downarrow$ a decrease of clinical important difference is a positive outcome. } \\
\hline \multicolumn{10}{|c|}{$\begin{array}{l}\text { Abbreviations: } 6 M W T=6 \text { Minute Walk Test, LINQ = Lung Information Needs Questionnaire, BCKQ = Bristol COPD Knowledge } \\
\text { Questionnaire, CAT =COPD Assessment Test, FPI-SF = Functional Performance Inventory-Short Form, MSEES = } \\
\text { Multidimensional Self-Efficacy for Exercise Scale, SE = Self-Efficacy, SEWS = Self-Efficacy for Walking Scale, SEAMS = Self- } \\
\text { Efficacy for Appropriate Medication Use Scale }\end{array}$} \\
\hline
\end{tabular}


The enhanced PR program was still being delivered at the $\mathrm{MCl} 18$ months after implementation. The same HCPs were involved in the program and participated in the study.

During the sustainability phase, 32 group education sessions were scored for implementation fidelity (Table 5). A good fidelity score was achieved for $82 \%$ of the items for content and $88 \%$ of the items for delivery. This was not significantly different from the implementation phase. The number of patients present at the group education sessions varied from 3 to 6 patients.

Data on exercise sessions was extracted for nine patients from their medical records. The duration of the program executed by the HCPs from the $\mathrm{MCl}$ was 6 or 7 weeks with 15 exercise sessions planned, but varied between individual patients from 5 to 12 weeks, with an average of 7 weeks which is between the recommended duration of 6 to 12 weeks. The number of exercise sessions varied from 9 to 27 sessions with an average of 15 sessions which is less than the minimal of 24 sessions which are recommended for the enhanced PR program. The recommendations of the enhanced PR program regarding home exercise, types of exercise, monitoring and the use of strategies to determine exercise intensity were followed by the $\mathrm{HCPs}$ at the $\mathrm{MCl}$.

Patient outcomes from the sustainability phase are shown in Table 8. Functional exercise capacity, knowledge, functional status, self-efficacy outcomes and some self-reported functional performance outcomes showed clinically important improvements for patients directly post-program. 
Table 8

Domain Effectiveness: Patient outcomes sustainability phase.

\begin{tabular}{|c|c|c|c|c|c|c|}
\hline Outcome & $\begin{array}{l}\text { Measurement } \\
\text { instrument }\end{array}$ & $\begin{array}{l}\text { Clinical important } \\
\text { difference }\end{array}$ & $\begin{array}{l}\text { Improved N } \\
(\%)^{*}\end{array}$ & $\begin{array}{l}\text { Not } \\
\text { improved } \\
\mathrm{N}(\%)^{* *}\end{array}$ & $\begin{array}{l}\text { Missing N } \\
(\%)\end{array}$ & $\begin{array}{l}\text { Total } \\
\text { N }\end{array}$ \\
\hline $\begin{array}{l}\text { Functional exercise } \\
\text { capacity }\end{array}$ & $6 \mathrm{MWT}$ & $\geq 33 \mathrm{~m} \uparrow$ & $4(44)$ & $4(44)$ & $1(11)$ & 9 \\
\hline \multirow[t]{2}{*}{ Knowledge } & LINQ & $\geq 1$ point $\downarrow$ & $3(33)$ & $2(22)$ & $4(44)$ & 9 \\
\hline & BCKQ, \%correct & $\geq 3 \% \uparrow$ & $1(11)$ & $4(44)$ & $4(44)$ & 9 \\
\hline Functional status & CAT-score & $\geq 2$ points $\downarrow$ & $5(56)$ & $2(22)$ & $2(22)$ & 9 \\
\hline \multirow{7}{*}{$\begin{array}{l}\text { Self-reported functional } \\
\text { performance }\end{array}$} & FPI-SF Body care & $\geq 0.5$ points $\uparrow$ & $0(0)$ & $5(56)$ & $4(44)$ & 9 \\
\hline & FPI-SF Household & $\geq 0.5$ points $\uparrow$ & $1(11)$ & $4(44)$ & $4(44)$ & 9 \\
\hline & $\begin{array}{l}\text { FPI-SF Physical } \\
\text { exercise }\end{array}$ & $\geq 0.5$ points $\uparrow$ & $1(11)$ & $4(44)$ & $4(44)$ & 9 \\
\hline & FPI-SF Recreation & $\geq 0.5$ points $\uparrow$ & $0(0)$ & $5(56)$ & $4(44)$ & 9 \\
\hline & FPI-SF Spiritual & $\geq 0.5$ points $\uparrow$ & $0(0)$ & $2(22)$ & $7(78)$ & 9 \\
\hline & FPI-SF Social & $\geq 0.5$ points $\uparrow$ & $2(22)$ & $3(33)$ & $4(44)$ & 9 \\
\hline & FPI-SF Total & $\geq 0.5$ points $\uparrow$ & $0(0)$ & $5(56)$ & $4(44)$ & 9 \\
\hline \multirow[t]{7}{*}{ Self-efficacy } & MSEES total mean & $\geq 10 \% \uparrow$ & $3(33)$ & $2(22)$ & $4(44)$ & 9 \\
\hline & Task SE & & $1(11)$ & $4(44)$ & $4(44)$ & 9 \\
\hline & Exercise coping & & $3(33)$ & $2(22)$ & $4(44)$ & 9 \\
\hline & Scheduling SE & & $3(33)$ & $2(22)$ & $4(44)$ & 9 \\
\hline & Breathing coping & & $2(22)$ & $3(33)$ & $4(44)$ & 9 \\
\hline & SEWS total mean & $\geq 10 \% \uparrow$ & $5(56)$ & $0(0)$ & $4(44)$ & 9 \\
\hline & SEAMS total mean & $\geq 10 \% \uparrow$ & $0(0)$ & $5(56)$ & $4(44)$ & 9 \\
\hline \multicolumn{7}{|c|}{${ }^{*}$ Number of patients that improved exceeding the clinical important difference. } \\
\hline \multicolumn{7}{|c|}{$\begin{array}{l}\text { ** Number of patients that did not improve or had an improvement that did not exceed the clinical important difference. Tan } \\
\text { increase of clinical important difference is a positive outcome. }\end{array}$} \\
\hline \multicolumn{7}{|c|}{$\downarrow$ a decrease of clinical important difference is a positive outcome. } \\
\hline \multicolumn{7}{|c|}{$\begin{array}{l}\text { Abbreviations: } 6 M W T=6 \text { Minute Walk Test, LINQ = Lung Information Needs Questionnaire, BCKQ = Bristol COPD Knowledge } \\
\text { Questionnaire, CAT =COPD Assessment Test, FPI-SF = Functional Performance Inventory-Short Form, MSEES = } \\
\text { Multidimensional Self-Efficacy for Exercise Scale, SE = Self-Efficacy, SEWS = Self-Efficacy for Walking Scale, SEAMS = Self- } \\
\text { Efficacy for Appropriate Medication Use Scale }\end{array}$} \\
\hline \multicolumn{7}{|c|}{ Abbreviations: $P R=$ Pulmonary Rehabilitation, $I C U=$ Intensive Care Unit } \\
\hline \multicolumn{7}{|c|}{ Abbreviations: $P R=$ Pulmonary Rehabilitation } \\
\hline
\end{tabular}

\section{Satisfaction, barriers and facilitators of the enhanced PR program (objective 3)}

Patient satisfaction was very high with an overall average score 9.5 out of 10 (SD 0.9) (Additional file 4). In the sustainability phase, patients were mostly very satisfied with the program components (Additional file 4). Since patients did not provide any comments on the survey of the implementation phase, the survey was changed for the sustainability phase to include more open- 
ended questions to get insight in barriers and facilitators for participation in the enhanced PR program as perceived by patients. Barriers that patients mentioned were: 1) bilingual group education sessions, 2) weather conditions and 3) long travel distance. Facilitators were: 1) participating in a group, 2) patient-specific adjustments of the program, 3) exercise and education sessions scheduled right after each other (reducing travel) and 4) being accompanied by someone.

Overall, HCPs were very satisfied with the enhanced PR program in the implementation phase, with an overall average score of 8.1 out of 10 (SD 1.4) (Additional file 4). They were less satisfied with the introduction of the program (mean score 6.7 SD 2.8) and the facilitator notes and resources for the education sessions (mean score 6.4, SD 3.4).

From the surveys for HCPs from both phases, barriers mentioned for implementation and sustainability of the PR program were: 1) lack of time, 2) having other priorities, 3) changes needed in slides, and 4) lack of French materials. Facilitators were: 1) longstanding procedure for assessments, 2) having a large team with many disciplines and 3) being familiar with LWWCOPD self-management program.

Results from the DIBQ (Additional file 4) show that $71.4-100 \%$ of HCPs $(N=7)$ agreed with the statements for 16 out of the 18 domains. This implies that the HCPs did not experience barriers for implementation within these 16 domains. The two remaining domains where a high percentage of the HCPs disagreed with the statements were Goals (57.1\% disagreed) and Socio-political context ( $40 \%$ disagreed). The domain Goals asks about how much of a priority the enhanced PR program is to a HCP and the domain Socio-political context asks how much support there is for PR from government and local authorities as perceived by the HCPs.

\section{Discussion}

This study provides, for the first time, a full evaluation of the implementation and sustainability of the enhanced PR program. We found that the enhanced PR program was successfully implemented at the $\mathrm{MCl}$ and accepted by both patients and $\mathrm{HCPs}$. Adoption was maximal for this study as all HCPs were willing to initiate the enhanced PR program. The program was maintained over 18 months with high program fidelity of the group education sessions and most of the exercise recommendations. Moreover, the HCPs were committed to further sustainment of the enhanced PR program. Our evaluation also showed that patients had clinical important improvements in functional capacity, knowledge, functional status and self-efficacy outcomes post-program and at 3-month follow-up. These improvements are in line with the body of evidence on the benefits of PR for individuals with COPD $^{1,24-27}$

With $70 \%$ (implementation phase) to $75 \%$ (sustainability phase) of the patients agreeing to do a rehab program, the reach of the overall enhanced PR program was high compared to other studies reporting uptake of PR ranging from $3-70 \% 28-30$. This great acceptability may be explained by the fact that referrers might have screened patients who were more likely to accept the referral to a PR program. There were a number of patients who did not participate in the enhanced PR program due to barriers which prevented them from attending a regular outpatient program. For example patients who were too frail to participate in the outpatient program received a prescription of a home exercise program. This finding highlights the need to improve access to a variety of PR programs that can be delivered in different contexts such as tele-medicine PR and home PR programs ${ }^{14,31}$ where the resources of the enhanced can be used as a standard. Measuring the reach of the enhanced PR program on individual (patient) level was limited within this single-centre study and there were no particular strategies used for increasing uptake of the program. In a larger study with multiple centers involved, a comparison of reach between these sites can be made.

Factors that contributed to the successful implementation at the $\mathrm{MCl}$ were that the HCPs were already working together for many years in an existing PR program and that they were familiar with the LWWCOPD program prior to implementation. In addition, the $\mathrm{MCl}$ has a very high number of professionals dedicated to the PR program $(\mathrm{N}=8)$ compared to data from a Canadian survey in $2015^{12}$ (median 4, interquartile range 3-6). It is expected that the implementation of the enhanced PR program into sites that have fewer HCPs available or with less experience with PR and/or self-management education or into sites where PR is not available yet, will be more challenging. In these settings, new barriers for implementation and sustainability of the program may be encountered. Finally, this project had strong support from the director of the PR program (JB) who was also an investigator in

Page $15 / 23$ 
this study. This might have influenced the willingness of the HCPs to contribute to the project and facilitated implementation. Therefore, it is important to evaluate the implementation of the enhanced PR programs in other settings in the future.

Our study has many strengths. To date, there are no studies that have systematically assessed the implementation of an evidence-based and comprehensive PR program. There is strong evidence for the effectiveness of PR on multiple outcomes in multiple populations ${ }^{1,8}$ but none on the process of implementing evidence-based PR into clinical sites $5,11,13$. Implementing evidence-based knowledge into practice is a complex process ${ }^{32-35}$ but can improve the quality of health care and patient outcomes $^{36}$. In addition, implementation projects with systematic evaluation are needed to help increase the accessibility of PR for patients with COPD ${ }^{11}$. Another strength of this study is the use of the RE-AIM framework, which ensured a rich program evaluation on multiple levels and on multiple domains in a real-life setting.

One of the limitations of the study is that only one site was included. This resulted in a small sample size and limited the analysis of patient outcomes using statistical tests. However, this was not the main focus of the study and by presenting the MCIDs the study still provided insights on the clinically meaningful effects of the program for patients with COPD.

With the experienced HCPs, the likelihood of a successful implementation was high for this site. Still, this study provides some lessons learned for future implementation of the enhanced PR program, which are: 1) A clearer introduction of the program based on the knowledge and experience of the HCPs on PR was needed, 2) The HCPs wanted to be better informed about the programs' resources (e.g. facilitator notes, presentation slides and reference guides for the group education sessions) and 3) HCPs should be allowed to adapt some of the programs' components for feasibility, such as the order of group education sessions and the slides used for these sessions.

\section{Conclusions}

In conclusion, this study showed a successful implementation of the enhanced PR program. Considering the added benefit of the enhanced PR program compared to traditional PR in terms of reducing healthcare utilization ${ }^{15}$, a next step would be further implementation and evaluation of the enhanced PR in a variety of settings including rural, community and tele-health settings which may or may not currently provide PR. The process and framework used in this study to evaluate the implementation of the enhanced PR can be of interest to researchers and clinicians who intend to implement PR programs in their sites. The enhanced PR program can be used by HCPs or healthcare managers to start a new program or increase the quality of an existing program. All resources and recommendations are available without cost on www.livingwellwithcopd.com (sign-up as a professional under the tab Canadian PR program).

\section{List Of Abbreviations}

6MWT: Six Minute Walk Test

ATS/ERS: American Thoracic and European Respiratory Societies

BCKQ: Bristol COPD Knowledge Questionnaire

BMl: Body Mass Index

BODE: Body mass index, airflow Obstruction, Dyspnea and Exercise capacity

CAT: COPD Assessment Test,

Cl: confidence interval

COPD: Chronic Obstructive Pulmonary Disease

CVD: Cardiovascular disease

Page 16/23 
DIBQ: Determinants of Implementation Behavior Questionnaire

FEV1: Forced Expiration Volume in one second

FPI-SF: Functional Performance Inventory Short Form

HADS: Hospital Anxiety and Depression Scale

HCPs: health care professionals

PR: Pulmonary rehabilitation

LINQ: Lung Information Needs Questionnaire

LWWCOPD: Living Well With COPD

MCl: Montreal Chest Institute

MCID: Minimal Clinical Important Difference

MRC-score: Medical Research Council score

MSEES: Multidimensional Self-Efficacy for Exercise Scale

$\mathrm{N}$ : number of patients

RE-AIM: Reach, Effectiveness, Adoption, Implementation and Maintenance

SD: standard deviation

SEAMS: Self-Efficacy for Appropriate Medication use Scale

SEWS: Self-Efficacy for Walking Scale

TDF: Theoretical Domains Framework

\section{Declarations}

\section{Ethics approval and consent to participate}

Ethical approval for this study was obtained from the Montreal University Health Centre Research Ethics Board (2018-3734 and 2019-5344). Written informed consent was obtained from all subjects before participation in the study.

\section{Consent for publication}

Not applicable.

\section{Availability of data and materials}

The datasets used and/or analysed during the current study are available from the corresponding author on reasonable request.

\section{Competing interests}

The authors declare that they have no competing interests.

\section{Funding}

This study was funded by the Edith Strauss Foundation. 


\section{Authors' contributions}

JW, M Sedeno, AMS, M Stickland, JB and TJF designed the enhanced PR program. KB, JW, CT, MS, JB and TJF designed the study. JW, CT, JB and TJF implemented the program at the MCI. KB, JW, CT and TP collected the data. KB analyzed the data. KB and TJF wrote the paper. All authors made substantial contributions to the interpretation of the data. JW, MS, AMS, MS and JB revised the manuscript critically for important intellectual content. All authors approved the final manuscript to be submitted for publication.

\section{Acknowledgements}

I would like to thank Sébastien Gagnon for his help with the collection of the data. My special thanks are extended to the staff of the PR program at the $\mathrm{MCl}$.

\section{References}

1. Vogelmeier CF, Criner GJ, Martinez FJ, et al. Global strategy for the diagnosis, management, and prevention of chronic obstructive lung disease 2017 report: GOLD executive summary. Am J Respir Crit Care Med. 2017. doi: 10.1164/rccm.201701-0218PP.

2. Wedzicha J, Seemungal TAR. COPD exacerbations: Defining their cause and prevention. Lancet. 2007;370(9589):786-796. doi: 10.1016/S0140-6736(07)61382-8.

3. Seemungal TA, Donaldson GC, Paul EA, Bestall JC, Jeffries DJ, Wedzicha JA. Effect of exacerbation on quality of life in patients with chronic obstructive pulmonary disease. Am J Respir Crit Care Med. 1998;157(5):1418-1422. doi: 10.1164/ajrccm.157.5.9709032.

4. Canadian Institute for Health Information. Inpatient hospitalizations, surgeries, Newborns and childbirth indicators, 20152016 (Ottawa: ClHI, 2016).

5. Marciniuk D, Brooks D, Butcher S, et al. Optimizing pulmonary rehabilitation in chronic obstructive pulmonary diseasepractical issues: A Canadian thoracic society clinical practice guideline. Can Respir J. 2010;17(4):159-168. doi: $10.1155 / 2010 / 425975$.

6. Nici L, Donner C, Wouters $\mathrm{E}$, et al. American thoracic society/european respiratory society statement on pulmonary rehabilitation. Am J Respir Crit Care Med. 2006;173(12):1390-1413. doi: 173/12/1390 [pii].

7. Odonnell DE. Canadian thoracic society recommendations for management of chronic obstructive pulmonary disease-2007 update. Canadian Respiratory Journal. 2007;14(Suppl B):5B. doi: 10.1155/2007/830570.

8. Spruit MA, Singh SJ, Garvey C, et al. An official American thoracic society/European respiratory society statement: Key concepts and advances in pulmonary rehabilitation. Am J Respir Crit Care Med. 2013;188(8):e13-e64. doi: 10.1164/rccm.201309-1634ST.

9. Criner GJ. Prevention of acute exacerbations of COPD: American college of chest physicians and canadian thoracic society guideline. Chest. 2015;147(4):894. doi: 10.1378/chest.14-1676.

10. Puhan M, Lareau S. Evidence-based outcomes from pulmonary rehabilitation in the chronic obstructive pulmonary disease patient. Clin Chest Med. 2014;35(2):295-301. doi: 10.1016/j.ccm.2014.02.001.

11. Rochester CL, Vogiatzis I, Holland AE, et al. An official american thoracic society/european respiratory society policy statement: Enhancing implementation, use, and delivery of pulmonary rehabilitation. American Journal Respirory Critical Care Medicine. 2015;192(11):1373-1386.

12. Camp PG, Hernandez P, Bourbeau J, et al. Pulmonary rehabilitation in canada: A report from the canadian thoracic society COPD clinical assembly. Canadian Respiratory Journal : Journal of the Canadian Thoracic Society. 2015;22(3):147-152. http://www.ncbi.nlm.nih.gov/pmc/articles/PMC4470547/.

13. Vogiatzis I, Rochester C, Spruit M, Troosters T, Clini E. Increasing implementation and delivery of pulmonary rehabilitation: Key messages from the new ATS/ERS policy statement. Eur Respir J. 2016;47(5):1336-1341. doi: 10.1183/13993003.021512015. 
14. Selzler A, Wald J, Sedeno M, et al. Telehealth pulmonary rehabilitation: A review of the literature and an example of a nationwide initiative to improve the accessibility of pulmonary rehabilitation. Chron Respir Dis. 2018;15(1):41-47. doi: $10.1177 / 1479972317724570$.

15. Selzler A, Jourdain T, Wald J, et al. Evaluation of an enhanced pulmonary rehabilitation program: A randomised controlled trial. submitted to Thorax. 2020.

16. Cosgrove D, Macmahon J, Bourbeau J, Bradley J, O'Neill B. Facilitating education in pulmonary rehabilitation using the living well with COPD programme for pulmonary rehabilitation: A process evaluation. BMC Pulm Med. 2013;13:50-50. doi: 10.1186/1471-2466-13-50.

17. Bourbeau J, Julien M, Maltais F, al e. Reduction of hospital utilization in patients with chronic obstructive pulmonary disease: A disease-specific self-management intervention. Arch Intern Med. 2003;163(5):585-591. http://dx.doi.org/10.1001/archinte.163.5.585.

18. Bourbeau J, Lavoie KL, Sedeno M. Comprehensive self-management strategies. Semin Respir Crit Care Med. 2015;36(4):630638. doi: 10.1055/s-0035-1556059.

19. Glasgow RE, Vogt TM, Boles SM. Evaluating the public health impact of health promotion interventions: The RE-AIM framework. Am J Public Health. 1999;89(9):1322-1327. doi: 10.2105/ajph.89.9.1322.

20. Gold RL. Roles in sociological field observations. Social Forces. 1958;36:217-223.

21. Cane J, O'Connor D, Michie S. Validation of the theoretical domains framework for use in behaviour change and implementation research. Implementation Science. 2012;7(1):37. doi: 10.1186/1748-5908-7-37.

22. Michie S, Johnston M, Abraham C, Lawton R, Parker D, Walker A. Making psychological theory useful for implementing evidence based practice: A consensus approach. Qual Saf Health Care. 2005;14(1):26-33. doi: 10.1136/qshc.2004.011155.

23. Kunstler BE. The self-reported factors that influence australian physiotherapists' choice to promote non-treatment physical activity to patients with musculoskeletal conditions. Journal of science and medicine in sport. 2019;22(3):275. doi: 10.1016/j.jsams.2018.08.006.

24. McAuley E, Courneya KS, Lettunich J. Effects of acute and long-term exercise on self-efficacy responses in sedentary, middleaged males and females. Gerontologist. 1991;31(4):534-542.

25. Hyland ME, Jones RCM, Hanney KE. The lung information needs questionnaire: Development, preliminary validation and findings. Respir Med. 2006;100(10):1807-1816. doi: 10.1016/j.rmed.2006.01.018.

26. Singh SJ, Puhan MA, Andrianopoulos V, et al. An official systematic review of the european respiratory society/american thoracic society: Measurement properties of field walking tests in chronic respiratory disease. Eur Respir J. 2014;44(6):14471478. doi: 10.1183/09031936.00150414.

27. Wise RA, Brown CD. Minimal clinically important differences in the six-minute walk test and the incremental shuttle walking test. COPD. 2005;2(1):125-129.

28. Foster F, Piggott R, Riley L, Beech R. Working with primary care clinicians and patients to introduce strategies for increasing referrals for pulmonary rehabilitation. Prim Health Care Res Dev. 2016;17(3):226-237. doi: 10.1017/S1463423615000286 [doi].

29. Zwar NA, Hermiz O, Comino E, et al. Care of patients with a diagnosis of chronic obstructive pulmonary disease: A cluster randomised controlled trial. Med J Aust. 2012;197(7):394-398. doi: 10.5694/mja12.10813.

30. Harris M. Providing reviews of evidence to COPD patients: Controlled prospective 12-month trial. Chronic Respiratory Disease. 2009;6(3):165. doi: 10.1177/1479972309106577.

31. Vieira DS, Maltais F, Bourbeau J. Home-based pulmonary rehabilitation in chronic obstructive pulmonary disease patients. Curr Opin Pulm Med. 2010;16(2):134-143. doi: 10.1097/MCP.0b013e32833642f2.

32. Harrison M, Légaré $F$, Graham I, Fervers B. Adapting clinical practice guidelines to local context and assessing barriers to their use. CMAJ. 2010;182(2):E78-E84. doi: 10.1503/cmaj.081232.

33. Peters D, Adam T, Alonge O, Agyepong I, Tran N. Republished research: Implementation research: what it is and how to do it. Br J Sports Med. 2014;48(8):731-736. doi: 10.1136/bmj.f6753. 
34. Kitson AL. Evaluating the successful implementation of evidence into practice using the PARiHS framework: Theoretical and practical challenges. Implementation Science. 2008;3(1):1. doi: 10.1186/1748-5908-3-1.

35. Graham I, Logan J, Harrison M, et al. Lost in knowledge translation: Time for a map? J Contin Educ Health Prof. 2006;26(1):13-24. doi: 10.1002/chp.47.

36. Grol R, Grimshaw J. From best evidence to best practice: Effective implementation of change in patients' care. Lancet. 2003;362(9391):1225-1230. doi: 10.1016/S0140-6736(03)14546-1.

\section{Figures}

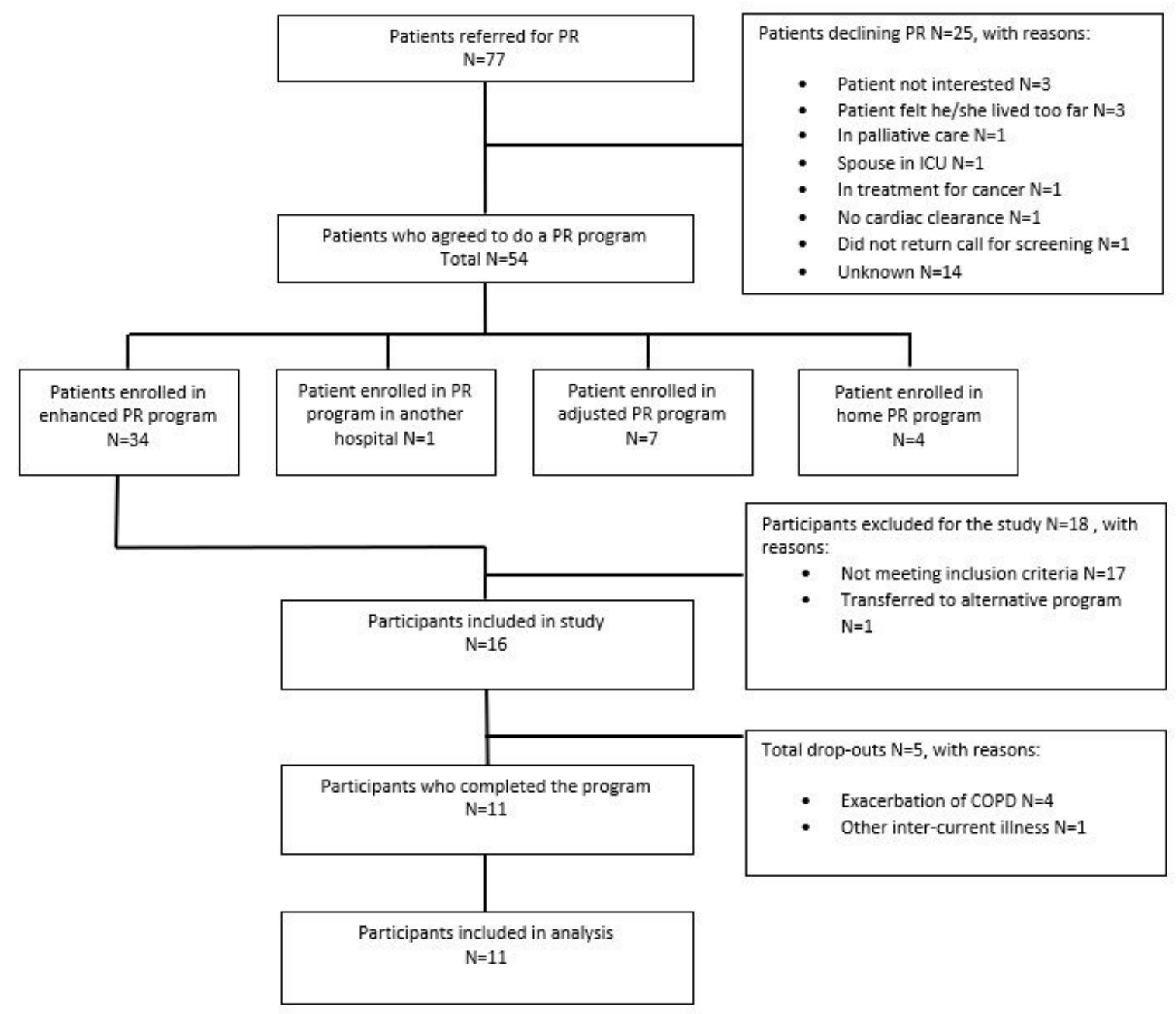

Abbreviations: $P R=$ Pulmonary Rehabilitation, $I C U=$ Intensive Care Unit

\section{Figure 1}

Domain Reach: Flowchart patient referral \& study inclusion for the pilot implementation phase. 


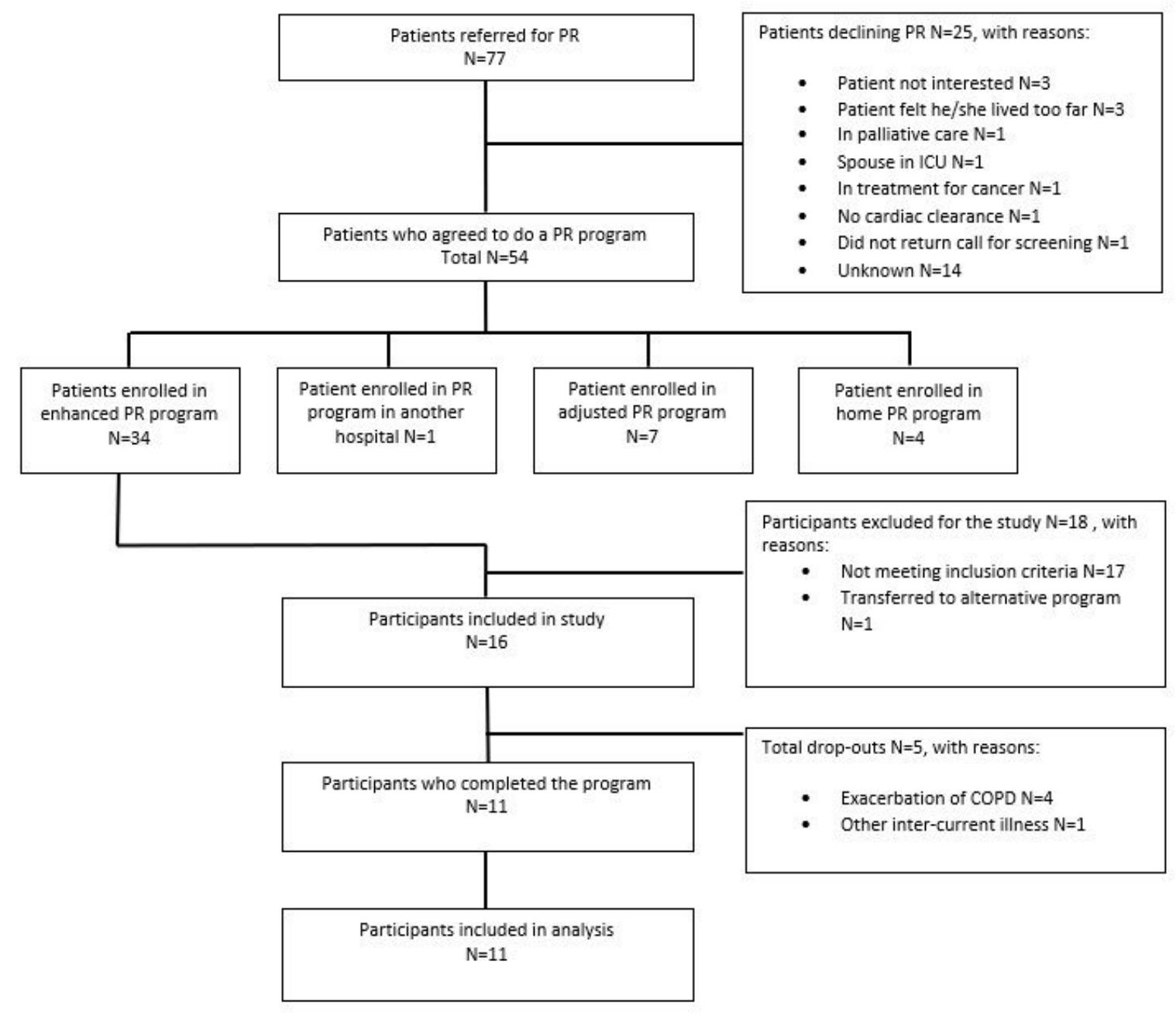

Abbreviations: $P R=$ Pulmonary Rehabilitation, $I C U=$ Intensive Care Unit

\section{Figure 1}

Domain Reach: Flowchart patient referral \& study inclusion for the pilot implementation phase. 


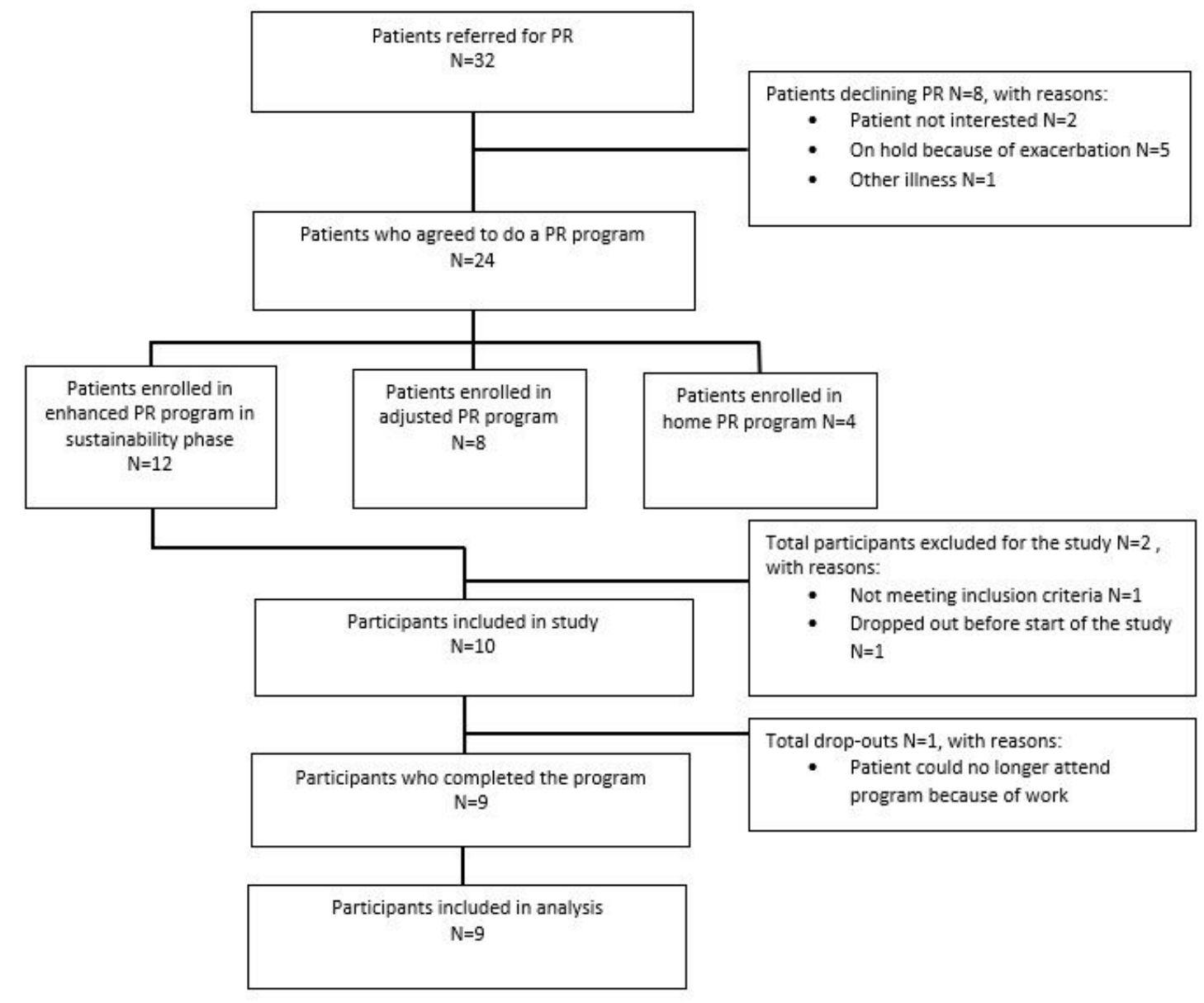

Abbreviations: $P R=$ Pulmonary Rehabilitation

\section{Figure 2}

Domain Reach: Flowchart patient referral \& study inclusion for the sustainability phase. 


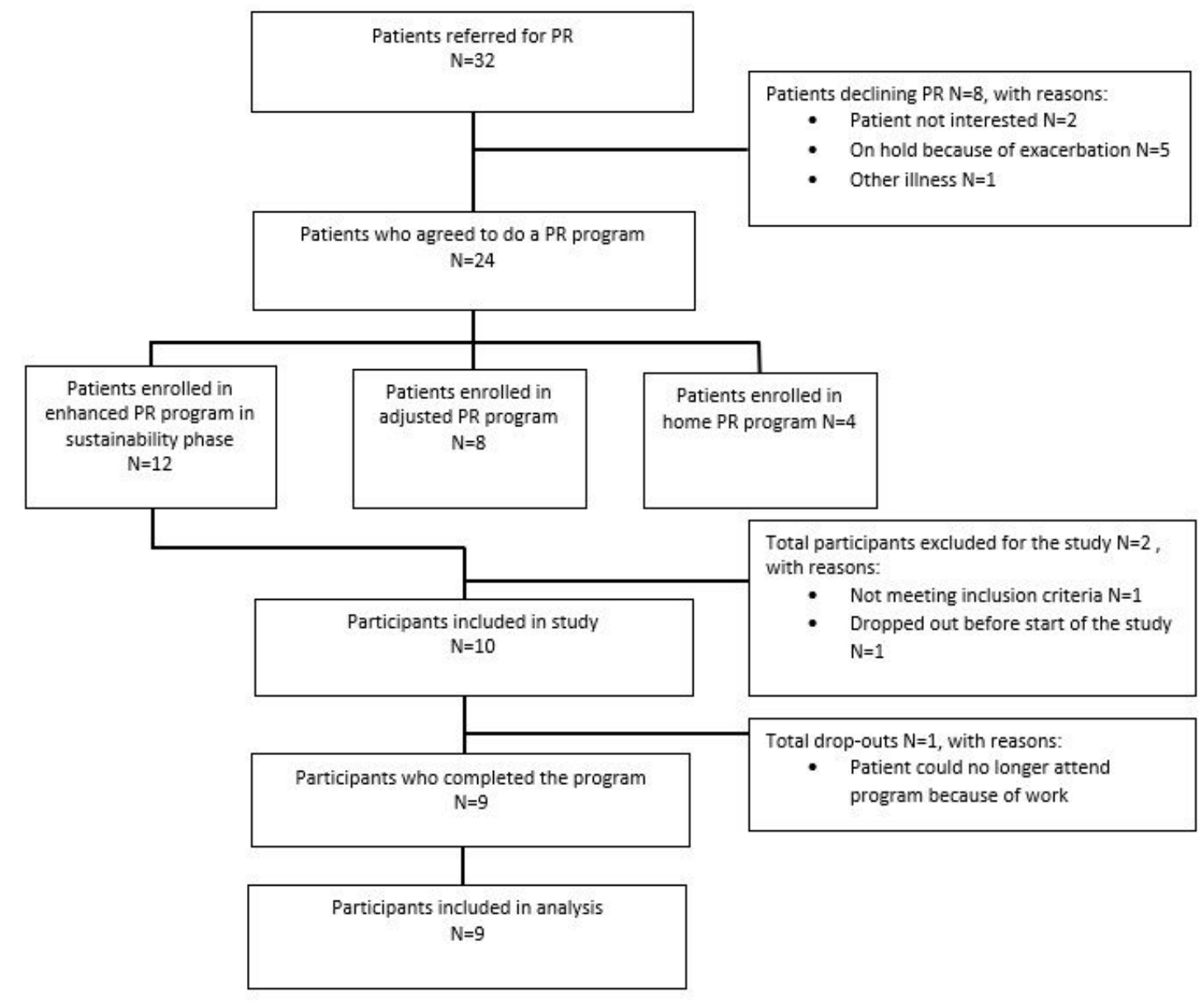

Abbreviations: $P R=$ Pulmonary Rehabilitation

Figure 2

Domain Reach: Flowchart patient referral \& study inclusion for the sustainability phase.

\section{Supplementary Files}

This is a list of supplementary files associated with this preprint. Click to download.

- Additionalfile1.docx

- Additionalfile1.docx

- Additionalfile2.docx

- Additionalfile2.docx

- Additionalfile3.docx

- Additionalfile3.docx

- Additionalfile4.docx

- Additionalfile4.docx 